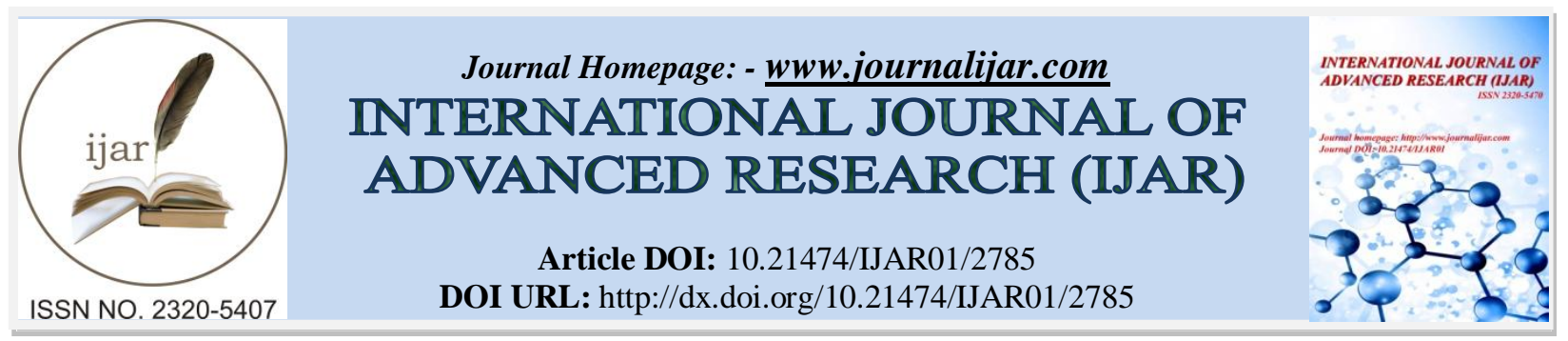

\title{
RESEARCH ARTICLE \\ DESIGN AND IMPLEMENTATION OF HIGH PERFORMANCE ANALOG CMOS BASED CIRCUITS USING PSPICE: AN OVERVIEW.
}

\section{Ayushi Chaurasia ${ }^{1}$ and Rajinder Tiwari ${ }^{2}$.}

1. M.Tech. Scholar (ECE), Amity School of Engineering and Technology, Amity University, Lucknow.

2. Department of Electrical and Electronics, Amity School of Engineering and Technology, Amity University, Lucknow

\section{Manuscript Info}

........................

Manuscript History

Received: 15 November 2016

Final Accepted: 17 December 2016

Published: January 2017

Key words:-

Cascode Current Mirror, IAFCCM,

Negative feedback gain, two stage current mirror.

\section{Abstract}

Current mirror is the basic key element in VLSI design. To obtain high performance analog circuit application, the output impedance and accuracy are the most important parameter to determine the performance of the current mirror. A new current mirror is proposed in this paper to provide high accuracy and very high output impedance. To increase the output impedance and matching accuracy significantly a novel feedback gain is used. The new proposed current mirror also has output swing similar as the traditional two stage cascode current mirror.

Copy Right, IJAR, 2016,. All rights reserved.

\section{Introduction:-}

Due to the better performance the current mode approach [1] - [5] is gaining interest more and more. The decreasing power supply voltage of digital micro electronics makes it suitable for mixed mode application is the reason for using current mode circuit. The current mirror is used for biasing or loading elements in analog circuit design. The most important parameter used to determine the performance of current mirror are accuracy and output impedance. It can be used to find many researches that focus on these two points. To increase the output impedance the cascode current mirror [6] and the RGC current mirror [9] is used. IAFCCM [8] was proposed to increase the accuracy. To achieve higher output impedance, multi stage cascode mirror has been used, although its suffer from low output voltage swing. The output impedance of the two stage cascode current mirror is lower than the output impedance of RGC current mirror and the accuracy of the RGC current mirror is not good enough for high precision application.

The accuracy of IAFCCM is better than RGC current mirror and the output impedance of IAFCCM is equivalent to the RGC current mirror. A new high output impedance current mirror is proposed in the paper to improve the accuracy and the output impedance of the new current mirror, it is based on the RGC circuit. To increase the output impedance and matching accuracy significantly a novel feedback gain stage is used. The new current mirror is similar to the traditional two stage cascode current mirror, so the proposed current mirror is better than that of RGC and IAFCCM.

Corresponding Author:- Ayushi Chaurasia. 
Description of previous circuits and the new current mirror:Previous current mirror circuits:-

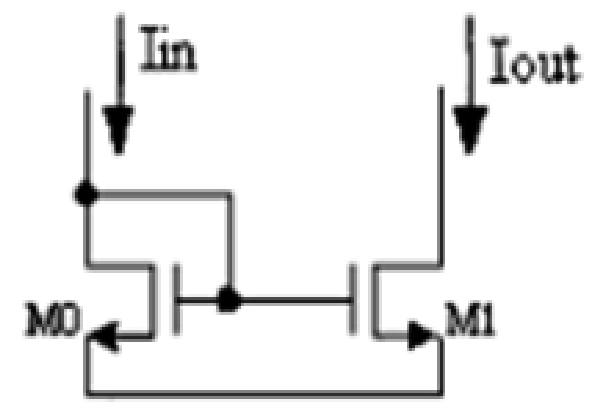

Fig. 1:- Traditional current mirror [1]

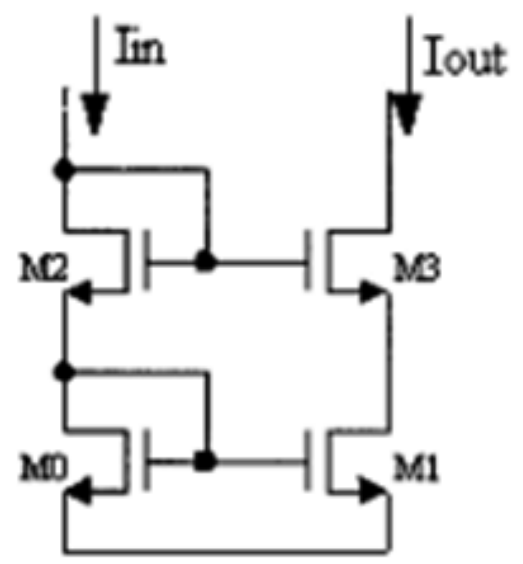

Fig 2:- Cascode current mirror [1]

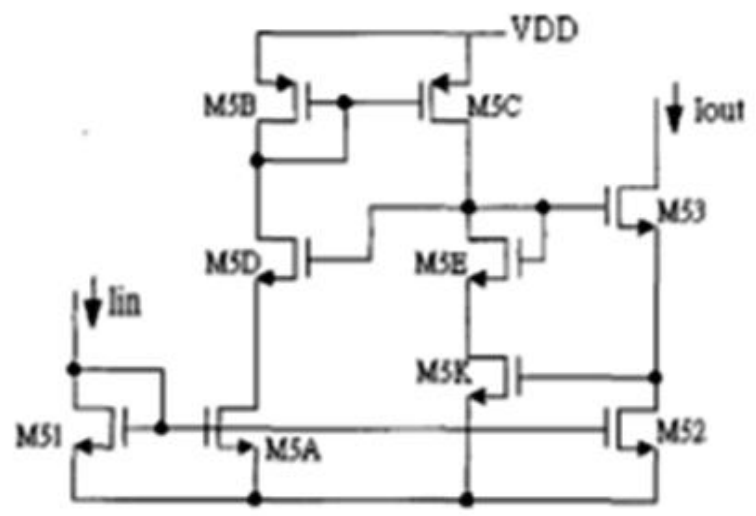

Fig 3:- IAFCCM [1]

The traditional current mirror is shown in fig.1. As the traditional current mirror's output impedance is not infinite, it will influence the output current $\mathrm{I}_{\mathrm{out}}$ by the variation of the output node voltage $\mathrm{V}_{\mathrm{ds}}$. It is a drawback in the analog circuits. In fig. 2 the cascode current mirror is shown. It has the matching accuracy [7] problem and it was proposed to improve the output impedance. In fig. 3 the IAFCCM is shown. It was proposed to increase the output impedance, 
output voltage swing and matching accuracy. IAFCCM improves lots of output voltage swing, but the output impedance is not high enough. Meanwhile the output node voltage influences the output current $\mathrm{I}_{\text {out }}$.

\section{The proposed new current mirror circuit:-}

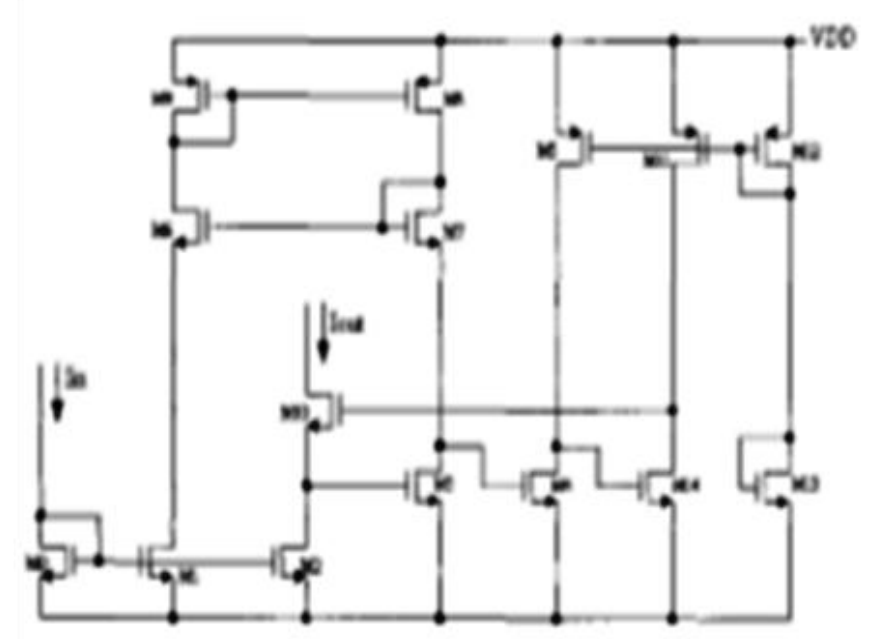

Fig 4:- The proposed current mirror [1]

The proposed new current mirror improves the new key parameters of the current mirror, the matching accuracy and output impedance. The fig. 4 shows the schematic diagram of the proposed new current mirror. Here are some MOS transistors such as M0, M2, M10 are used as a two stage cascode current mirror and some MOS transistors such as M1, M6, M9, M7 and M8 are used to improve the matching accuracy of the cascode current mirror. M3, M4 and M14 are the three novel negative feedback gain stages that can increase the output impedance of the current mirror significantly.

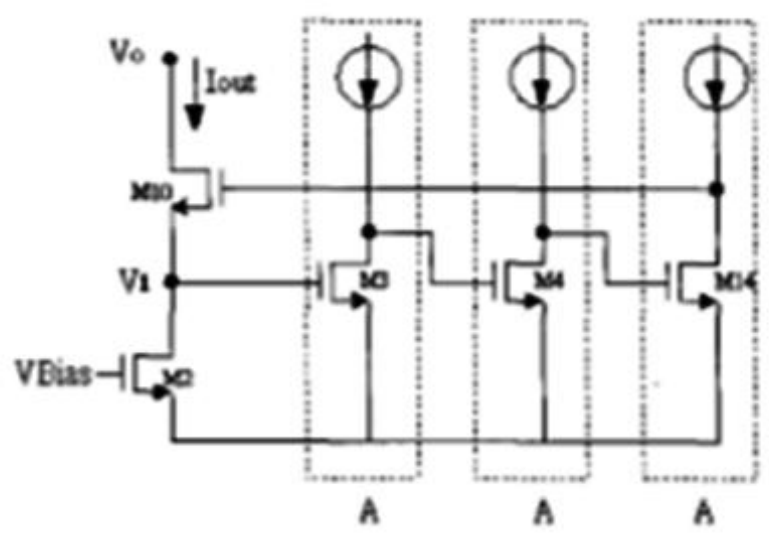

Fig 5:- The feedback circuit [1]

The feedback circuit of the current mirror is shown in fig.5 and the voltage gain of each gain stage is shown as A. The output impedance are out of the new proposed current mirror can be estimated by following.

$\mathrm{V}_{1}==i \frac{1}{g d_{2}}$

$i=g m_{10} *\left(-|\mathrm{A}|^{3}-1\right) * \mathrm{~V}_{1}+g d_{10} *\left(\mathrm{~V}_{0}-\mathrm{V}_{1}\right)$

$$
\begin{gathered}
=>i *\left(1+\frac{g m_{10}}{g d_{2}}|A|^{3}+\frac{g m_{10}}{g d_{2}}+\frac{g d_{10}}{g d_{2}}\right)=g d_{10} * V_{0} \\
=>\frac{V_{0}}{i}=\left(1+\frac{g m_{10}}{g d_{2}}|A|^{3}+\frac{g m_{10}}{g d_{2}}+\frac{g d_{10}}{g d_{2}}\right) \div g d_{10}
\end{gathered}
$$




$$
=\frac{g m_{10}}{g d_{10}}|A|^{3} \frac{1}{g d_{2}}
$$

$R_{0}=\frac{g m_{10}}{g d_{10}} \frac{1}{g d_{2}}|A|^{3}$

As shown in equation (4) where $\mathrm{A} \cong-\frac{g m_{i}}{g d_{i}}$ ( $\mathrm{i}=3,4$ and 14 respectively), the proposed new current mirror has much larger $\mathrm{R}_{\mathrm{out}}$ than that of the IAFCCM which has output impedance $R_{\text {out }}=g m_{53} g m_{5 k} \frac{1}{g d_{52}} \frac{1}{g d_{53}}\left[\frac{1}{g d_{5 k}} / / \frac{1}{g d_{5 c}}\right]$

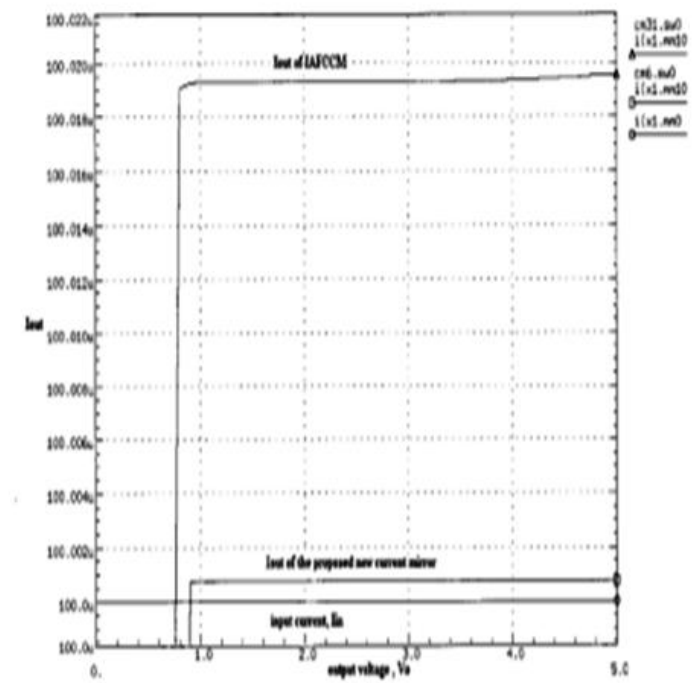

Fig 6:- The I-V curve of the simulation result [1]

In fig. 5 the voltage $V_{1}$ is independent of $V_{0}$. When $V_{0}$ and $V_{1}$ are increased then the $V_{\text {ds14 }}$ is decreased due to the three gain stages. The negative feedback signal is created by connecting $\mathrm{V}_{\mathrm{ds} 14}$ to the gate of $\mathrm{M}_{10}$. Therefore decrease in $\mathrm{V}_{\mathrm{ds} 14}$ decrease the $\mathrm{V}_{1}$. Thus the negative feedback loop locks $\mathrm{V}_{1}$ so that a stable $\mathrm{I}_{\text {out }}$ is obtained. Now the proposed new current mirror has high output impedance.

For a good current mirror another factor is the matching accuracy [10] between $\mathrm{I}_{\text {in }}$ and $\mathrm{I}_{\text {out }}$. The MOS transistors $\mathrm{M}_{6}$, $\mathrm{M}_{7}, \mathrm{M}_{8}$ and $\mathrm{M}_{9}$ are used to match the current $\mathrm{I}_{\mathrm{m} 1}$ and $\mathrm{I}_{\mathrm{m} 2}$ in the new proposed circuit and further make $\mathrm{V}_{\mathrm{Gs} 3}=\mathrm{V}_{\mathrm{Gs} 1}$. From $V_{\mathrm{Gs} 1}=\mathrm{V}_{\mathrm{Gs} 0}=\mathrm{V}_{\mathrm{Ds} 0}$ and $\mathrm{V}_{\mathrm{Gs} 3}=\mathrm{V}_{\mathrm{Ds} 2}$, we can find $\mathrm{V}_{\mathrm{Ds} 2}=\mathrm{V}_{\mathrm{Ds} 0}$ which results $\mathrm{I}_{\mathrm{in}=} \mathrm{I}_{\mathrm{out}}$. The proposed new current mirror has better matching accuracy than the IAFCCM and it is proved by the HSPICE simulation results.

\section{Simulation Results:-}

The HSPICE simulation results are based upon $0.35 \mu \mathrm{m} 1 \mathrm{P} 4 \mathrm{M}$ CMOS process which has a supply voltage of $3.3 \mathrm{~V}$

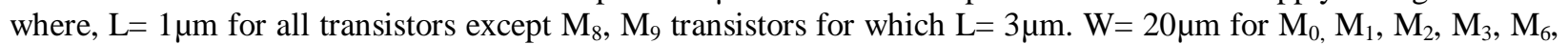
$\mathrm{M}_{7}, \mathrm{M}_{10}$ and

$\mathrm{W}=40 \mu \mathrm{m}$ for $\mathrm{M}_{8}, \mathrm{M}_{9}$ to ensure $\mathrm{I}_{\text {out }}=100 \mu \mathrm{A}$

$\mathrm{W}=5 \mu \mathrm{m}$ for $\mathrm{M}_{4}, \mathrm{M}_{14}$

$\mathrm{W}=10 \mu \mathrm{m}$ for $\mathrm{M}_{5}, \mathrm{M}_{11}$

$\mathrm{W}=1 \mu \mathrm{m}$ for $\mathrm{M}_{12}, \mathrm{M}_{13}$

The I-V curve simulation result of the proposed new current mirror and IAFCCM is shown in fig.6. The I-V plot of the input current $\mathrm{I}_{\mathrm{in}}$ is the lowest line. The top line is the I-V plot of IAFCCM, it shows that the output impedance is not that much high to avoid the influence of $V_{d s}$ i.e. under the variation of the output voltage $V_{0}$ the $I_{\text {out }}$ will be changed. The I-V plot of the proposed circuit is the middle line and it indicates that the output impedance of the proposed circuit is higher than IAFCCM. In fig.6 the comparison results of the accuracy is shown. The proposed circuit has a matching accuracy better than IAFCCM when the input current $\mathrm{I}_{\text {in }}=100 \mu \mathrm{A}$. 
Table 1:- The proposed CM performance comparison with IAFCCM [1]

\begin{tabular}{|c|c|c|}
\hline Issue & $\begin{array}{c}\text { The proposed } \\
\text { circuit }\end{array}$ & IAFCCM \\
\hline $\begin{array}{c}\text { Mirroring error } \\
\text { lin=5uA }\end{array}$ & $0.016 \%$ & $0.036 \%$ \\
\hline $\begin{array}{c}\text { Mirroring error } \\
\text { lin=10uA }\end{array}$ & $0.012 \%$ & $0.03 \%$ \\
\hline $\begin{array}{c}\text { Mirroring error } \\
\text { lin=100uA }\end{array}$ & $0.001 \%$ & $0.019 \%$ \\
\hline $\begin{array}{c}\text { Mirroring error } \\
\text { lin=200uA }\end{array}$ & $0.005 \%$ & $0.015 \%$ \\
\hline $\begin{array}{c}\text { Mirroring error } \\
\text { lin=300uA }\end{array}$ & $0.012 \%$ & $0.014 \%$ \\
\hline $\begin{array}{c}\text { Mirroring error } \\
\text { lin=400uA }\end{array}$ & $0.026 \%$ & $0.013 \%$ \\
\hline Rout & $\propto \frac{1}{g d}\left(\frac{\mathrm{gm}}{\mathrm{gd}}\right)^{4}$ & $\propto \frac{1}{\mathrm{gd}}\left(\frac{\mathrm{gm}}{\mathrm{gd}}\right)^{2}$ \\
\hline
\end{tabular}

Table 1 shows the comparison result between the proposed circuit and IAFCCM under various input circuit. Input current changes from $5 \mu \mathrm{A}$ to $400 \mu \mathrm{A}$. When the input current is lower than $400 \mu \mathrm{A}$ due to the MOS transistor sizes of the proposed circuit are smaller than IAFCCM. But the output impedance $\mathrm{R}_{\text {out }}$ of the proposed new circuit is larger than that of the IAFCCM.

\section{Conclusion:-}

A high output impedance and high accuracy current mirror is proposed and analyzed in this paper. According to the simulation results the accuracy and the output impedance of the proposed circuit is better than IAFCCM. The proposed current mirror is much suitable for using in high linearly, high output impedance current output stages and the operational amplifiers design.

\section{Acknowledgement:-}

The authors are thankful to Mr. Aseem Chauhan (Additional President, RBEF and Chancellor AUR, Jaipur), Maj. General K. K. Ohri (AVSM, Retd.) Pro-VC, Amity University, Uttar Pradesh Lucknow, Prof. S. T. H. Abidi (Director ASET, Lucknow Campus), Brig. U. K. Chopra (Director AIIT \& Dy. Director ASET), Prof O. P. Singh (HOD, Electrical \& Electronics), Prof. H. K. Dwedi (Dy. Director, Research in Electronics) and Prof. N. Ram (Dy. Director ASET) for their motivation, kind cooperation, and suggestions.

\section{Reference:-}

1. Kuo-Hsing Cheng, Chi-Che Chen and Chun-Fu Chung "Accurate Current Mirror with High Output Impedance"

2. Handkiewicz, A.; Kropidlowski, M.; Lukowiak, M. "Switched-current technique for video compression and quantization" ASIC/SOC Conference, 1999. Proceedings. Twelfth Annual IEEE International , 1999 Page(s): 299 -303

3. Harb, A.; Sawan, M. "New low-power low-voltage high-CMRR CMOS instru- mentation amplifier" Circuits and Systems, 1999. ISCAS '99. Proceedings of the 1999 IEEE International Symposium on , Volume: 6, 1999 Page(s): 97 -100 01.6

4. Zeki, A.; Kuntman, H. "High-output- im- pedance CMOS dual-output OTA suitable for wide-range continuous time filtering applications” Electronics Letters, Volume: 35 Issue: 16, 5 Aug. 1999 Page(s): 1295 -1296

5. Nooshabadi, S.; Visweswaran, G.S.; Nagchoudhurhi, D. "Current mode ternary D/A converter" VLSI Design, 1998. Proceedings., 1998 Eleventh International Conference on , 1998 Page(s):244 - 248

6. P. E. Allen and D. R. Holberg, “CMOS Analog Circuit Design”. New York: Holt, Rinehart and Winston, 1987 Page(s):233

7. Song, B.G.; Chang, I.K.; Kwon, O.J.; Park, J.G.; Kwack, K.D. "A simulation-based analog cell synthesis with improved simu- lation efficiency" TENCON 99. Proceedings of the IEEE Region 10 Conference , Volume: 2, 1999 Page(s): 1018 $1021 \mathrm{v} 01.2$

8. Zeki, A.; Kuntman, H. "Accurate and high output impedance current mirror suitable for CMOS current output stages" Electronics Letters, Volume: 33 Issue: 12 , 5 June 1997 Page(s): 1042 -1043.

9. Saclunger, E.; Guggenbuhl, W. "A high-swing, high-impedance MOS cascode circuit" Solid-state Circuits, IEEE Journal of, Volume: 25 Issue: 1, Feb. 1990 Page(s): 289 -29

10. B. Razavi, Principles of Data Conversion System Design. New York: IEEE Press, 1995. 